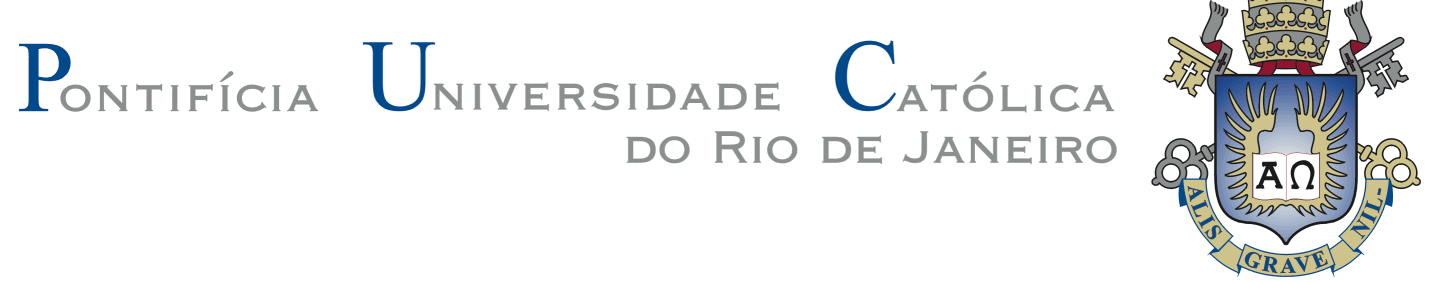

Felipe Wircker Machado

\title{
UMA OU VÁRIAS PELES: SOBRE O CORPO INACABADO
}

\section{Dissertação de Mestrado}

Dissertação apresentada como requisito parcial para obtenção do grau de Mestre pelo Programa de Pós-Graduação em Literatura, Cultura e Contemporaneidade do Departamento de Letras do Centro de Teologia e Ciências Humanas da PUC-Rio.

Orientadora: Profa. Ana Paula Veiga Kiffer 


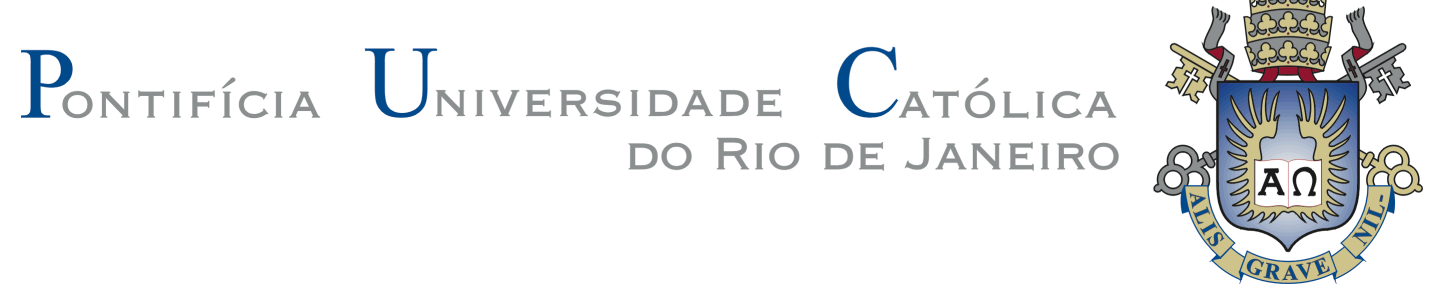

Felipe Wircker Machado

\title{
UMA OU VÁRIAS PELES: SOBRE O CORPO INACABADO
}

\begin{abstract}
Dissertação apresentada como requisito parcial para obtenção do grau de Mestre pelo Programa de Pós-Graduação em Literatura, Cultura e Contemporaneidade do Departamento de Letras do Centro de Teologia e Ciências Humanas da PUC-Rio. Aprovada pela Comissão Examinadora abaixo assinada.
\end{abstract}

Profa. Ana Paula Veiga Kiffer
Orientadora
Departamento de Letras - PUC-Rio

Profa. Eneida Leal Cunha

Departamento de Letras - PUC-Rio

Prof. Marcelo Gustavo Lima de Campos

UERJ

Profa. Denise Berruezo Portinari

Coordenadora Setorial do Centro de Teologia

e Ciências Humanas - PUC-Rio

Rio de Janeiro, 12 de abril de 2013 
Todos os direitos reservados. É proibida a reprodução total ou parcial do trabalho sem autorização da universidade, do autor e do orientador.

\section{Felipe Wircker Machado}

Graduou-se em Comunicação Social, com habilitação em Jornalismo, pela Pontifícia Universidade Católica do Rio de Janeiro em 2009. Cursou Pós-graduação Lato Sensu em Literatura, Arte e Pensamento Contemporâneo pela mesma instituição. Participou de congressos na área de gênero e sexualidade. Sua pesquisa tem como enfoque produções artísticas e teórico-críticas que atravessam questões como corpo, gênero, sexualidade e ativismo queer.

Ficha Catalográfica

Machado, Felipe Wircker

Uma ou várias peles: sobre o corpo inacabado / Felipe Wircker Machado ; orientadora: Ana Paula Veiga Kiffer. - 2013.

216 f. : il. (color.) ; $30 \mathrm{~cm}$

Dissertação (mestrado)-Pontifícia Universidade Católica do Rio de Janeiro, Departamento de Letras, 2013.

Inclui bibliografia

1. Letras - Teses. 2. Corpo. 3. Inacabado. 4. Humano. 5. Humanismo. 6. Inumano. 7. Intruso. 8. Animal. 9. Sexualidade. 10. Gênero. 11. Sexo. I. Kiffer, Ana Paula Veiga. II. Pontifícia Universidade Católica do Rio de Janeiro. Departamento de Letras. III. Título. 
À minha mãe e ao meu pai 


\section{Agradecimentos}

À Capes, pela bolsa de pesquisa que me foi concedida durante o curso de mestrado, e pela bolsa-sanduíche que viabilizou minha missão de estudos na Universidad Nacional de Rosario.

Às pessoas que aqui nomeio, qualquer tentativa de agradecimento será sempre insuficiente. Às amizades, verdadeiros acontecimentos durante esse início de um percurso em processo, agradeço imensamente os afetos, o carinho, o apoio e a confiança, e dedico todo o meu afeto sincero.

Aos meus pais e à minha irmã;

À professora Ana Kiffer, minha orientadora;

A Carla Rodrigues;

A Elizabeth Muylaert Duque-Estrada,

A Marília Rothier Cardoso;

A Adriana Azevedo, Joana Rabelo, Mayumi Aibe, Natalie Araújo Lima, Rafael Meire;

Aos professores e professoras que, em sala de aula ou fora dela, me movimentaram, instigaram e ajudaram: Eneida Leal Cunha, Flávia Vieira, Helena Martins, Paulo Cesar Duque-Estrada, Rosana Kohl Bines, Roberto Corrêa dos Santos e Vera Follain de Figueiredo;

A Daniele de Oliveira Cruz e Francisca Ferreira de Oliveira, pela atenção e gentileza de sempre;

À professora Julieta Yelín, pelas sugestões de leitura;

Às amizades que me acompanharam e compartilharam comigo estes dois anos: Adriano Ennes, Diego Paleólogo, Eduardo Senna, Eloise Porto, Gabriel Vignoli, Julia Shimura, Lucas de Freitas, Lucas Viriato, Luiza Sposito Vilela, Marina Alves, Maurício Hoelz, Michele Nojima, Paloma Malaguti, Paula Campello, Pedro Bernardes, Yara Henriques;

A Delfina Cabrera, Fernanda Nogueira, Javier Gasparri, Lorena Faccio, Moira Pérez e Matheus Santos;

Às pessoas que conheci no Grupo de Pesquisa e Ações Acadêmicas Trans 


\section{Resumo}

Machado, Felipe Wircker; Kiffer, Ana Paula Veiga. Uma ou várias peles: sobre o corpo inacabado. Rio de Janeiro: 2013. 216 p. Dissertação de Mestrado - Departamento de Letras, Pontifícia Universidade Católica do Rio de Janeiro.

Nesta dissertação, busca-se pensar a noção de inumano em suas implicações com o poder instituído e instituinte de formas de vida "humanas" a partir de duas vertentes: a questão do animal e as questões de gênero e sexualidade, apontando que estas são indissociáveis daquelas, ou de uma problematização do humanismo e da noção de "humano". Percorre-se, para isso, um grupo heterogêneo de registros, dando ênfase ao cruzamento entre realizações estéticas e críticofilosóficas. A partir do filme A pele que habito, de Pedro Almodóvar, e de alguns trabalhos da artista plástica Louise Bourgeois são destacadas as questões a serem trabalhadas ao longo da pesquisa. A questão do inumano ergue-se do texto $O$ intruso, de Jean-Luc Nancy, para pensar esta noção não mais como par opositivo do humano. Acerca da fronteira entre humano e animal, propõe-se um encontro, não desprovido de tensões, entre textos de Jacques Derrida, Giorgio Agamben, e Gilles Deleuze \& Félix Guattari. A sexualidade é abordada a partir do cruzamento entre ensaios fotográficos contemporâneos e textos teórico-críticos relativos a gênero e sexualidade, questionando o entendimento do corpo como algo fechado, fixado ao rigor dos binarismos de classificações identitárias, para privilegiar, a partir da potência de corpos não conformes a tais categorias, uma noção de corpo como algo inacabado, aberto às possibilidades de outros modos de vida, espaço potente de desmonte da norma heterossexual.

\section{Palavras-chave}

Corpo; inacabado; humano; humanismo; inumano; intruso; animal; sexualidade; gênero; sexo 


\section{Resumen}

Machado, Felipe Wircker; Kiffer, Ana Paula Veiga (Directora). Una o varias pieles: sobre el cuerpo inacabado. Rio de Janeiro: 2013. 216 p. Tesis de Maestría - Departamento de Letras, Pontifícia Universidade Católica do Rio de Janeiro.

En esta tesis, se busca pensar la noción de inhumano en sus relaciones con el poder establecido y establecedor de formas de vida "humanas" a partir de dos vertientes: la cuestión del animal y las cuestiones de género y sexualidad, subrayando que estas son indisociables de aquellas, o de una problematización del humanismo y de la noción de "humano". La pesquisa recorre, para esto, un grupo heterogéneo de resgistros, dando énfasis al cruce entre realizaciones estéticas y crítico-filosóficas. A partir de la película La piel que habito, de Pedro Almodóvar, y de algunos trabajos de la artista plástica Louise Bourgeois son planteadas las cuestiones que serán trabajadas a lo largo de la pesquisa. La cuestión del inhumano se yergue del texto El intruso, de Jean-Luc Nancy, para pensar esta noción no más como par opositivo del humano. Acerca de la frontera entre humano y animal, se propone un encuentro, no desproveído de tensiones, entre textos de Jacques Derrida, Giorgio Agamben, Gilles Deleuze y Félix Guattari. La sexualidad es abordada a partir del cruce entre ensayos fotográficos contemporáneos y textos teórico-críticos relativos a género y sexualidad, cuestionando el entendimiento del cuerpo como algo cerrado, fijado al rigor de los dualismos de clasificaciones identitarias, para privilegiar, a partir de la potencia de cuerpos no conformes a dichas categorías, una noción de cuerpo como algo inacabado, abierto a las posibilidades de otros modos de vida, espacio potente de desmonte de la norma heterosexual.

\section{Palabras clave}

Cuerpo; inacabado; humano; humanismo; inhumano; intruso; animal; sexualidad; género; sexo 


\section{Sumário}

1. Introdução

2. A pele que habito e o corpo inacabado

2.1. Fazer uma Vênus

2.2. "Pense que a sua vida depende desse orifício, que você respira por ele"

2.3. "O rosto nos identifica"

2.4. "Já não posso continuar a te chamar de Vicente" 36

2.5. "Posso dar-me por terminada?"

3. O intruso: o inumano, o animal

3.1. Acerca do intruso e da forma-Homem

3.2. Acerca do humano e do animal

4. Nudez, sexo e gênero: de corpos não conformes

4.1. Acerca da nudez

4.2. Acerca do sexo 90

4.3. Acerca do gênero e da invenção da transexualidade

5. Ainda nu: acerca da política das identidades e dos modos de vida

6. Conclusão 
O corpo, a pele: todo o resto é literatura anatômica, fisiológica e médica. Músculos, tendões, nervos e ossos, humores, glândulas e órgãos são ficções cognitivas. São formalismos funcionalistas. Mas a verdade é a pele. Está na pele, faz pele: autêntica extensão exposta, completamente orientada ao fora ao mesmo tempo que envoltório do dentro, do saco cheio de ruídos e de cheiro de umidade. A pele toca e se faz tocar. A pele acaricia e afaga, se lastima, se esfola, se rasga. É irritável e excitável. Toma sol, frio e calor, vento, chuva, inscreve marcas de dentro rugas, espinhas, verrugas, escoriações - e marcas de fora, às vezes as mesmas, ou ainda rachaduras, cicatrizes, queimaduras, cortes. 